\title{
Success of linezolid therapy for postneurosurgical ventriculitis due to vancomycin-resistant Enterococcus faecium: case report and literature review
}

\author{
Jia-Ji Qiu ${ }^{1,2,3,4^{*}}$, Jie Tang ${ }^{1,2,3,4}$ and De-Ling Li $i^{1,2,3,4}$
}

\begin{abstract}
Background: Vancomycin-resistant Enterococcus faecium ventriculitis is one of the most severe events in postneurosurgical intracranial infections. There are no guidelines recommending an appropriate treatment before.

Case presentation: This case presents a successful linezolid treatment for post-neurosurgical vancomycin-resistant Enterococcus faecium ventriculitis of a 24-year-old man in the department of neurosurgery, Beijing Tiantan Hospital.

Conclusions: Linezolid should be considered as one of the important methods for the treatment of post-

neurosurgical intracranial infections caused by vancomycin-resistant Enterococcus.
\end{abstract}

Keywords: Vancomycin-resistant Enterococcus (VRE), Linezolid (LZD), Neurosurgery

\section{Background}

Hospital acquired infection is a tough medical problem existing in many medical treatments. The most common causes are surgical-site-related, catheter-related, and ventilator-associated infections. Some of them may lead to severe results. Neurosurgical site infection often appears as meningitis or ventriculitis, which are considered critical infectious diseases and may lead to the death of the patient. Nosocomially acquired intracranial infections may be caused by a wide array of microorganisms, including staphylococci, enterococci, Gram-negative bacilli and yeasts. However the pathogen such as vancomycin-resistant Enterococcus (VRE) is very rare in intracranial infections. We report a successful case of linezolid treatment for post-neurosurgical vancomycinresistant Enterococcus faecium ventriculitis.

\section{Case presentation}

A 24-year-old man who had presented with diplopia, headache, right side myasthenia and bucking

\footnotetext{
* Correspondence: qiujiaji@yeah.net

${ }^{1}$ Department of Neurosurgery, Beijing Tiantan Hospital, Capital Medical University, Tiantanxili 6, Dongcheng District, Beijing 100050, China

${ }^{2}$ China National Clinical Research Center for Neurological Diseases, Beijing, China Full list of author information is available at the end of the article
}

symptoms, was admitted to Beijing Tiantan Hospital for treatment. The MRI revealed a suprasellar cistern tumor. Then he underwent right frontotemporalorbitozygomatic approach craniotomy for the suprasellar cistern tumor resection. The pathology of tumor was notochordoma. One week after the operation, the CSF leakage appeared. So the patient underwent the second operation to repair the CSF leakage and also got the lumbar cistern drainage. After the surgical intervention, the patient developed a middle-grade fever and altered consciousness. The white blood cell count rose up, so the antimicrobial treatment was initialized with Ceftazidime, Piperacillin and Sulbactam. There is no sign of infection improvement. The body temperature of the patient kept between $38{ }^{\circ} \mathrm{C}$ to $39{ }^{\circ} \mathrm{C}$. And the white blood cell count kept between $12 \times 10^{9} / \mathrm{L}$ and $18 \times 10^{9} / \mathrm{L}$. The conscious state of the patient worsened day by day. Twenty days later, the patient developed acute hydrocephalus and brain hernia. The lateral ventricular puncture external drainage was performed immediately. It helped the patient to recover form coma. However the ventriculitis appeared. The cerebrospinal fluid (CSF) obtained from lateral ventricular 
Table 1 Susceptibility results of the pathogen vancomycinresistant Enterococcus (VRE) faecium

\begin{tabular}{|c|c|}
\hline Antimicrobials & $\mathrm{MIC}$ \\
\hline Ampicillin & $R(>8)$ \\
\hline Gent.Synergy & $R(>500)$ \\
\hline Imipenem & $N / R$ \\
\hline Levofloxacin & $R(>4)$ \\
\hline Linezolid & $S(2)$ \\
\hline Oxacillin & $>2$ \\
\hline Penicillin & $\mathrm{R}(>8)$ \\
\hline Tazobae & $>8$ \\
\hline Rifampin & $R(>2)$ \\
\hline Strep.Synergy & $S(\leq 1000)$ \\
\hline Synercid & $S(0.5)$ \\
\hline Amox/k Clav & $>4 / 2$ \\
\hline Trimeth/Sulfa & $>2 / 38$ \\
\hline Tetracycline & $S(\leq 4)$ \\
\hline Vancomycin & $R(>16)$ \\
\hline Chloramphenicol & $S(\leq 8)$ \\
\hline Clindammycin & $>2$ \\
\hline Cefazolin & $>16$ \\
\hline Ciprofloxacin & $\mathrm{R}(>2)$ \\
\hline Erythromycin & $R(>4)$ \\
\hline Nitrofurantoin & $\leq 32$ \\
\hline Gentamicin & $>8$ \\
\hline
\end{tabular}

MIC minimum inhibitory concentration $(\mu \mathrm{g} / \mathrm{ml}), R$ resistant, $S$ sensitive, I intermediate

puncture external drainage was yellow, turbidity and flocculent. And the white blood cell count of CSF rose up to more than $2000 / \mu \mathrm{L}$. The antimicrobial treatment changed to amikacin, meropenem and vancomycin for ten days. Later the vancomycinresistant Enterococcus (VRE) faecium was isolated from the CSF culture. It was resistant to vancomycin and imipenem, but sensitive to linezolid (LZD). Thus linezolid was administrated intravenously $600 \mathrm{mg}$ $\mathrm{q} 12 \mathrm{~h}$ for half a month. It resulted in a resolution of the ventriculitis and a negative CSF culture. The following occipital ventriculoperitoneal shunt procedure resulted in a cure Figs. 1, 2, 3 and 4. (Table 1).

\section{Discussion}

Nosocomial infections are important medical problems in neurosurgical patients. Among the nosocomial infections, meningitis and ventriculitis are fearful infections and can lead to severe complications even death. The reported incidence of postoperative meningitis is quite variable $(0.5-8 \%)$ [1-5]. The incidence of ventriculitis is even lower.

Post-neurosurgical intracranial infections are mostly caused by a wide array of microorganisms. It is reported that the most common organisms causing meningitis are non-fermentative Gram-negative bacteria (NFGNB) (27.3 \%), followed by Pseudomonas aeruginosa (15.6 \%) and Klebsiella species (12.6\%). A study of 18092 patients who underwent neurosurgical procedures at the department of neurosurgery, National Institute of Mental Health and Neurological Sciences, Bangalore, India during 2001 to 2007, showed that 415 patients developed infection such as meningitis. Only 9 patients of them developed to enterococcus meningitis [6]. Vancomycin-resistant Enterococcus (VRE) ventriculitis occurs extremely rare. So far there are no guidelines recommending an appropriate treatment.

Linezolid (LZD) is the first licensed member of the oxazolidinone class of antibiotics. It has good activity against almost all Gram-positive pathogens, including multidrug-resistant organisms such as methicillin-resistant Staphylococcus aureus (MRSA) and vancomycin-resistant Enterococcus (VRE) faecium [7]. The unique mechanism

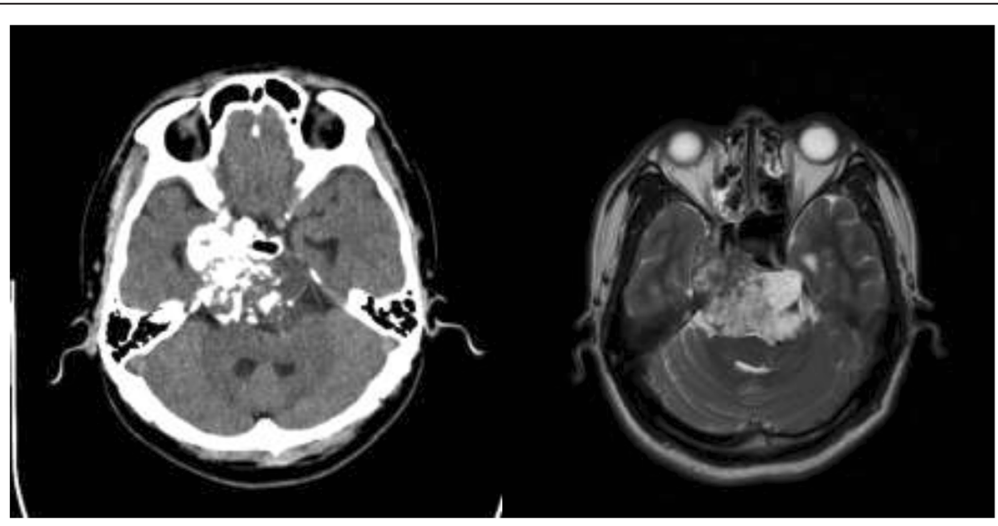

Fig. 1 Preoperative CT and MRI without contrast of the brain reveals a suprasellar cistern tumor 


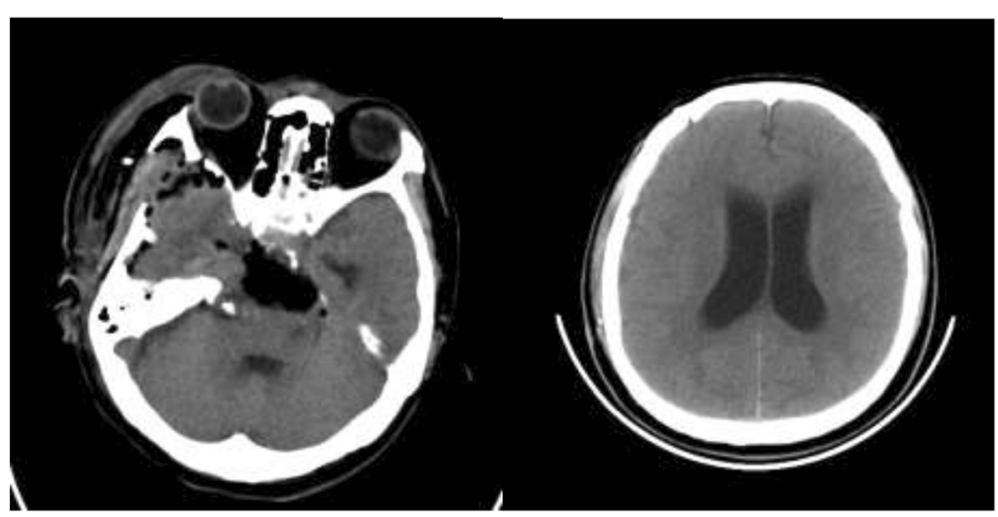

Fig. 2 Postoperative $C T$ reveals the tumor removal but hydrocephalus 20 days after the second operation

of linezolid, that involves inhibition of bacterial protein synthesis at a very early stage of the process, makes cross-resistance between linezolid and other classes of antibacterial agents unlikely [8]. Excellent tissue penetration and great oral bioavailability are notable properties of linezolid. Thus it allows sequential intravenous-to-oral administration without changing the drug or dosage regimen. It is approved in Europe and the USA for the treatment of nosocomial pneumonia, skin and soft tissue infections; and in the USA vancomycin-resistant Enterococcus (VRE) faecium and methicillin-resistant Staphylococcus aureus (MRSA) infections [9]. Linezolid is reported to have good penetration into the CNS [10]. A study in Japan showed the penetration of LZD into the CSF was $58.9 \%$ of the peak value and $133 \%$ of the trough value of serum concentrations following intravenous administration. And the penetration of LZD into the CSF was $82.9 \%$ of the peak value and $145.6 \%$ of the trough value of serum concentrations following oral administration [11]. For patients with a range of serious Gram-positive infections, including those caused by suspected or proven multidrug-resistant pathogens such as VRE or MRSA, linezolid can be an effective and generally well tolerated therapeutic option. In spite of this, gastrointestinal adverse effects are relatively common with linezolid and also associated with thrombocytopenia and myelosuppression [7]. Thus if the adverse effects occur, the doses and treatment period should be reduced.

In this case, the pathogen caused ventriculitis of the patient was vancomycin-resistant Enterococcus (VRE) faecium. It was resistant to many antimicrobials but sensitive to LZD. LZD administrated intravenously $600 \mathrm{mg}$ q12h for half a month, followed by lumbar cistern drainage and VP shunt, led to an excellent outcome. Post-neurosurgical intracranial infections are critical severe events. The appropriate use of antibiotics is a key point. The antibiotics should be sensitive to pathogens and have good penetration into the CNS. The appropriate neurosurgical intervention is also very important, such as lateral ventricular puncture external

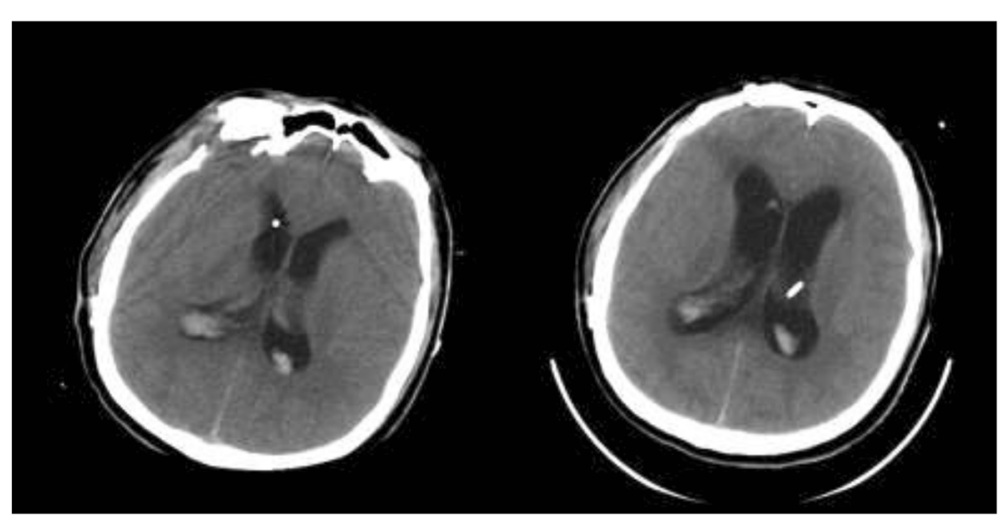

Fig. 3 Postoperative CT reveals the appearance of ventriculitis and the performance of lateral ventricular puncture external drainage 


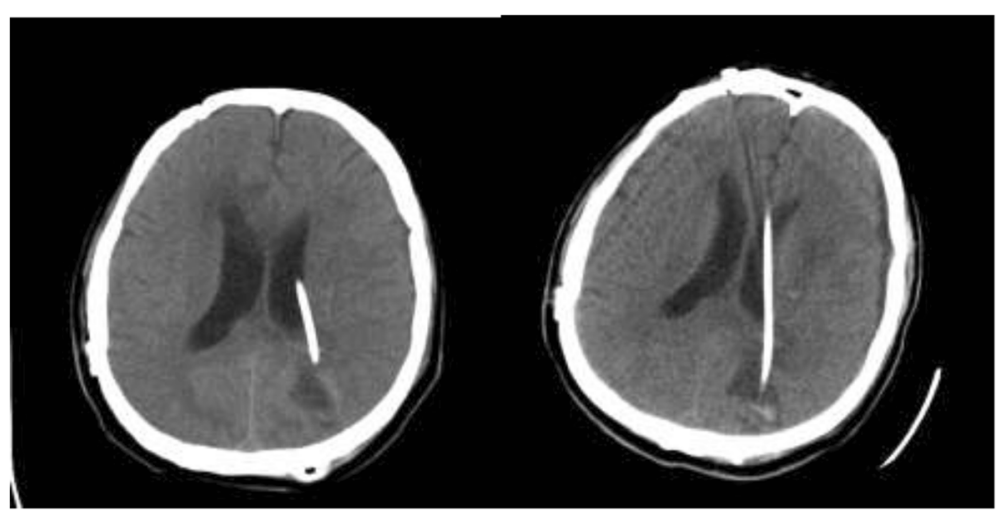

Fig. 4 Postoperative CT reveals the resolution of the ventriculitis and hydrocephalus, after the use of linezolid and the ventriculoperitoneal shunt procedure

drainage, lumbar cistern drainage, and VP shunt. Multiple methods led to the cure of post-neurosurgical vancomycin-resistant Enterococcus faecium ventriculitis in this case.

\section{Conclusion}

LZD should be considered as one of the important methods for the treatment of post-neurosurgical intracranial infections caused by vancomycin-resistant Enterococcus.

\section{Abbreviations}

CNS: central nervous system; CSF: cerebrospinal fluid; LZD: linezolid; MRSA: methicillin-resistant Staphylococcus aureus; NFGNB: non-fermentative Gram-negative bacteria; VP: ventriculoperitoneal; VRE: vancomycin-resistant Enterococcus.

\section{Competing interests}

The authors declare that they have no competing interests.

\section{Authors' contributions}

JT and DLL contributed with JJQ to write the report. JJQ and JT contributed in clinical treatment of the case. JJQ contributed in drafting the manuscript. JT and DLL contributed in revising the manuscript. All authors read and approved the final manuscript.

\section{Acknowledgements}

We thank the medical staff of the Department of Neurosurgery, Beijing Tiantan Hospital, for their help in the treatment of the case.

\section{Author details}

'Department of Neurosurgery, Beijing Tiantan Hospital, Capital Medical University, Tiantanxili 6, Dongcheng District, Beijing 100050, China. ${ }^{2}$ China National Clinical Research Center for Neurological Diseases, Beijing, China. ${ }^{3}$ Center of Brain Tumor, Beijing Institute for Brain Disorders, Beijing, China. ${ }^{4}$ Beijing Key Laboratory of Brain Tumor, Beijing, China.

Received: 2 July 2015 Accepted: 17 October 2015

Published online: 18 December 2015

\section{References}

1. Dashti SR, Baharvahdat H, Spetzler RF, Sauvageau E, Chang SW, Stiefel MF, et al. Operative intracranial infection following craniotomy. Neurosurg Focus. 2008:24, E10.

2. Tenney JH, Vlahov D, Salcman M, Ducker TB. Wide variation in risk of wound infection following clean neurosurgery. Implications for perioperative antibiotic prophylaxis. J Neurosurg. 1985;62:243-7.
3. McClelland 3rd S, Hall WA. Postoperative central nervous system infection: Incidence and associated factors in 2111 neurosurgical procedures. Clin Infect Dis. 2007:45:55-9.

4. Sharma MS, Vohra A, Thomas P, Kapil A, Suri A, Chandra PS, et al. Effect of risk-stratified, protocol-based perioperative chemoprophylaxis on nosocomial infection rates in a series of 31927 consecutive neurosurgical procedures (1994-2006). Neurosurgery. 2009;64:1123-30.

5. Kourbeti IS, Jacobs AV, Koslow M, Karabetsos D, Holzman RS. Risk factors associated with post craniotomy meningitis. Neurosurgery. 2007;60:317-26.

6. Srinivas D, Veena Kumari HB, Somanna S, Bhagavatula I, Anandappa CB. The incidence of postoperative meningitis in neurosurgery: an institutional experience. Neurol India. 2011;59(2):195-8.

7. Plosker GL, Figgitt DP. Linezolid: a pharmacoeconomic review of its use in serious Gram-positive infections. Pharmacoeconomics. 2005;23(9):945-64.

8. Fung HB, Chang JY, Kuczynski S. A practical guide to the treatment of complicated skin and soft tissue infections. Drugs. 2003;63(14):1459-80.

9. Wilcox MH. Efficacy of linezolid versus comparator therapies in Grampositive infections. J Antimicrob Chemother. 2003;51 Suppl 2:ii27-35.

10. Villani P, Regazzi MB, Marubbi F, Viale P, Pagani L, Cristini F, et al. Cerebrospinal fluid linezolid concentrations in postneurosurgical central nervous system infections. Antimicrob Agents Chemother. 2002;46:936-7.

11. Nagashima G, Okamoto N, Okuda M, Nakashima K, Noda M, Itokawa H, et al. Effect of linezolid against postneurosurgical meningitis caused by methicillin-resistant Staphylococcus epidermidis: case report. J Infect Chemother. 2008;14(2):147-50. Epub 2008 Apr 30.

\section{Submit your next manuscript to BioMed Central and take full advantage of:}

- Convenient online submission

- Thorough peer review

- No space constraints or color figure charges

- Immediate publication on acceptance

- Inclusion in PubMed, CAS, Scopus and Google Scholar

- Research which is freely available for redistribution

Submit your manuscript at www.biomedcentral.com/submit
BioMed Central 